\title{
HOW TO PREPARE AND APPEAR FOR EXAMINATIONS - A PSYCHOLOGICAL STUDY
}

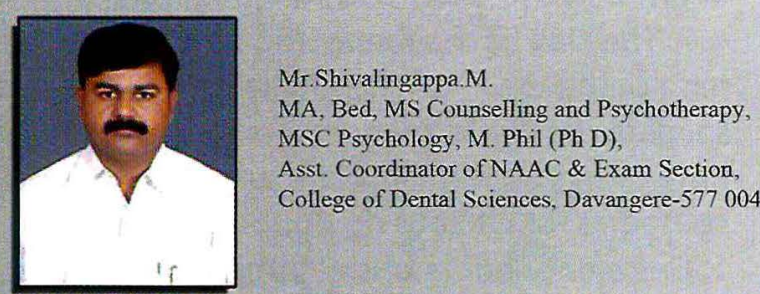

1. Introduction: Examinations are to formal learning as races are to Olympic training. They are the final performance for which the participant must travel a long road of preparation. The exam, like the race, is only a small part of the story. There are many long hours, weeks and months of serious training that must be undertaken before the examinee and competitor can even hope to be at his best on the fateful day. This will focuses on methods of preparing for emanations followed by tips for success in examination and trading choosing the answers and finally dealing with examination anxiety.
2. Objectives:
1. Methods of preparing for examinations
2. Tips for success in examination
3. Methods of choosing the answer
4. Dealing with examination anxiety

3.1. Examination Preparation: Of all the stress-relief coping techniques there are, the strategy that works best is to be as prepared as humanly possible. Nothing eliminates anxiety as well as knowing what expect and being ready for it.

3.1.1. During your Course: the best approach for good long-term preparation is to look at the entire year or semester as per exam studying. Because there is often a long time between the classes and the first major exam. Students usually fail to make a strong link in their minds between regular studying and the frantic cramming that accrues in the days and hours before the exam itself. In fact, it's all exams studying, and should work to develop that attitude.

3.1.2. Know what is Expected: As early as possible in the course, make sure you get a clear

picture of what is expected of you. How many exams and tests will there be? How much is each worth? When will they be scheduled? Keep track of all your pending exams by writing them down on a calendar. 3.1.3. Make a Plan:You are better off making a definite plan about your priorities and study timing than simply reacting to each looming exam as a crisis situation. Remember, if you don't plan to control your work, it will soon control you.

3.1.4. Do the Reading: Do the required reading for each course. Don't fall so far behind that you will be in danger of missing basic material. You must spend your pre exam study doing proper, effective study reading with activate note making along the way.

3.1.5. Go to Every Class: Don't skip classes. Don't sit passively in your lecture waiting to be taught. Make a commitment to be an active learner in each and every class.

3.1.6. Regularly Review: Do the regular review of reading and lecture notes recommended in to review of study reading technique. Regular review throughout the school term is the key.

\subsection{Immediately before the exam-the}

"homestretch": In the week or few days immediately preceding the examination, you need to shift from the steady reading, note making, and review stage in to an intensive study phase.

Step-01, Gather all material: There is only short time in which to review what you've and activate it for the exam. Take an extremely organized approach. The first step in that process is gathering together all the material you need to review: textbooks, lecture notes, reading note, lab books, seminar handoutseverything.

\section{Step-02, Make a schedule:}

Schedule enough time to ensure that you cover all the essential information and topics.

Step-03: 30-Minute overview of material: Spend no more than $\$ 30$ minutes on this step. Think of it as a warm-up.

Step-04: Create a menu of what you need to know: Step-05: Practice A LOT of output: After the initial review, $90 \%$ of the rest of your preparation time should be spending on output activities. These include, but are not limited to-

1. Teaching it to someone else. 
2. Making flash cards and using them.

3. Mnemonic devices

4. Mind maps

5. Giving a speech

6. Creating a speech

7. Other pictures or doodles

8. Writing

Test yourself: Construct your own essay questions and practice answering them in the same time you are likely to be given during the real exam.

If you have experienced difficulty in exam situations before, testing yourself is not only a good way to solidify the course content in your long-term memory, but you can also practice function in the artificial atmosphere of the exam room.

3.3. Practical Details: You can also prepare yourself for the exam situation by anticipating the practical things can go wrong and cause serious problems for your exam performance.

1. Know the format of the exam (is it one hour or three hours? It is multiple-choice essays or problem -solving?).

2. Be certain of the time and place of the exam. If it's scheduled to be in a room or building you are not familiar with, go for a visit in advance. It helps to visualize your success and easy handling of the situation if you can picture the actual site. Find out where the nearest bathroom is to your exam site.

3. Buy extra pens, pencils, batteries and other items you will need to take with you. If you have medication that you may need, make sure you have an adequate supply.

4. If you are seeing a ride the exam or taking the bus, double-cheek the schedule and arrangements. Plan to arrive early. It's always a bad to arrive late or just in the nick of time but panting for breath. Planning to be at the exam site early also allows for something to go wrong and still gives you time to get there.

3.4. Anticipation as a study guide: Ask the instructor what will be on the exam. Most teachers are willing to give you some direction. If not brainstorming with other classmates.

\subsection{Dealing with anxiety: Preparation of the course} material is the intervention strategy for anxiety. If the uncertainty of your performance on the test is making you anxious and nervous-do something about study. The whole process and individual strategies discussed earlier are designed to help you take control of the problem. Severe anxiety is a tell tale symptom of the problem having control over you.

\section{Writing the Exam: tips for Success:}

4.1. The Day of the Exam: the time before the beginning of the exam can be crucial to how well you consolidate the conformation you have worked with and how calm you remain. Here are some basic tips and strategies for what to do during this time.

1. Get plenty hours of sleep the night before, At this point an hour of sleep is more valuable to your performance than an hour of extra cramming.

2. In the hours immediately before the exam, don't try learning anything new, using this time to review and rehearse what you already know. Practice output, don't read passively.

3. Time and regulate your eating and drinking according to the principles set out. (Don't eat a heavy meal, don't drink alcohol, and don't use a lot of diuretics, such as coffee).

4. Arrive eariy

5. Use positive visualization and self-talk. Imagine yourself doing well, recalling easily and calmly dealing with uncertainly and difficult questions.

6. Review your anxiety strategies. If you're really ready, you probably won't get an anxiety attack, but at least you will be ready if you do.

7. Find a seat where you feel most comfortable (e.g. heat if you tend to fell cold, or by a window for fresh air). Arrive early enough to get the seat you want.

8. Generally, avoid talking to other nervous students. It will feed your anxiety and inhabit your concentration. Focus on the material and your certain feelings of mastery over it.

9. Have all your materials ready (extra pens, pencils, calculator, extra batteries, and any other material you are allowed to bring in). Pick it all night before and have it aiding for you by the door.

Have all your materials ready (extra pens, pencils, calculator, extra batteries, and any other material you are allowed to bring in). Pick it all night before and have it aiding for you by the door.

4.2. General Principles for all Exams: Strategies for specific kinds of exam structure are given below. There are, however, some principles that are valid or all forms of exam and exam situation.

1. Stay for the whole exam

2. Ignore what others are doing

3. Read all directions carefully

4. Budget your time wisely

5. Do what you are confident of first 
A. Multiple-Choice Strategies: the main part of a statement that is completed by one the several alternatives offered below it. The questions may also be in the form of a question to which you select appropriate responses from the choice given.

1. Do the easy questions first. Skip the difficult ones and go back them later. Plan to make three passes through the questions, first for the easy ones, second for those you have to think and work hard to answer, and a third time for those where your response will be more than $50 \%$ guess -work. Your goal is to make certain you answer all the easy ones first and get those marks. Getting struck on hard ones early in the exam not only wastes time, but builds frustration that blocks the free flow of recall. The confidence building that occurs as you get several questions correct will relax you and help your recall for the more difficult questions later.

4.3. Essay Exams: Remember, you are writing only one essay, but the examiner will be reading and grading many. Keep that in mind as you write. You should make it easy for the reader to read and understand your essay, don't make it harder on the reader than you have to.

1. Take time to plan and outline your answer.

2. It you more than one essay question. Do the brain storming an outlining for all the questions before beginning to write.

3. When writing, get to the point immediately-do not waste words.
6. Summary: The harder you work at the output activities and testing yourself, the stronger your confidence will be. Doubts, worries, trepidation and uncertainty are all normal feelings before any type of performance. There is nothing wrong with having this level of anxiety and it is unlikely to inhibit your best results. In fact, a reasonable level of fear heightens awareness and reaction to me. However, extreme levels of fear and panic will block access to higher brain function.

\section{References:}

1. Nnelson.R. \& Jones-1995. Theory and Practice of Counselling, London, Holt \& Rinehart Winston Ltd.

2. Coreeg.G.-1991, Theory and Practice of Counselling and Psychotherapy, 4th ed. California, Brooks Cole Publishing Co.

3. Swaminathan.V.D \& Kaloappan.K.V.-1997, Psychology for Effective Living-behavior Modification, Counselling, guidance and Yoga, Chennai, The Madras Psychology Society.

4. Patterson.L.E. \& Welfel.E.F.-2000. The Counselling Process 5th Edition, California, Wadsworth.

5. Gudykunsi.W.B., Ting-Toomey.S., Sudweeks.S. \& Stewart.L.P.-1995. Building Bridges, International Skills for a Changing World, Houghton Mifflin Co.

6. Hargie.O., Saunders.C. \& Dickson.D.-1994, Social Skills Interpersonal Communication (Publisher).

\section{SOCIAL ACTIVITIES}

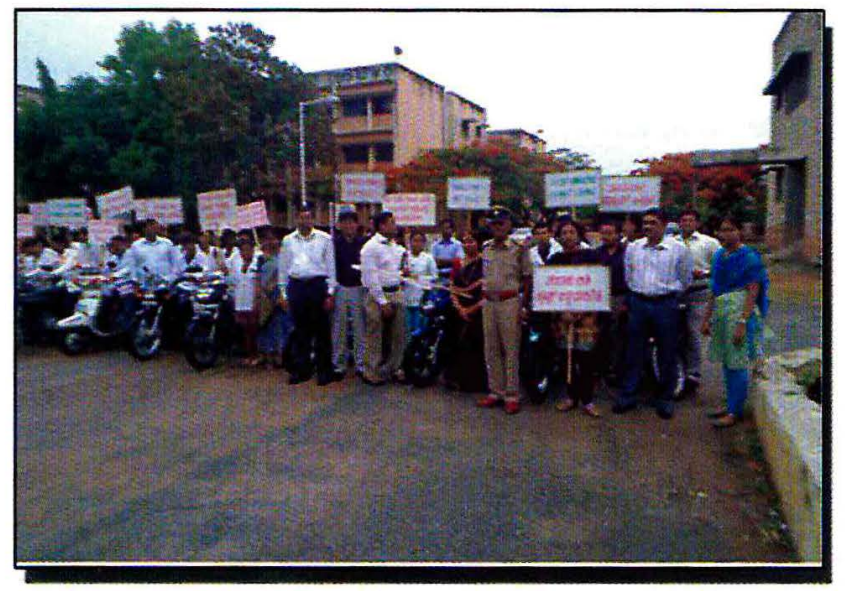

Anti tobacco day held on 31/5/2011

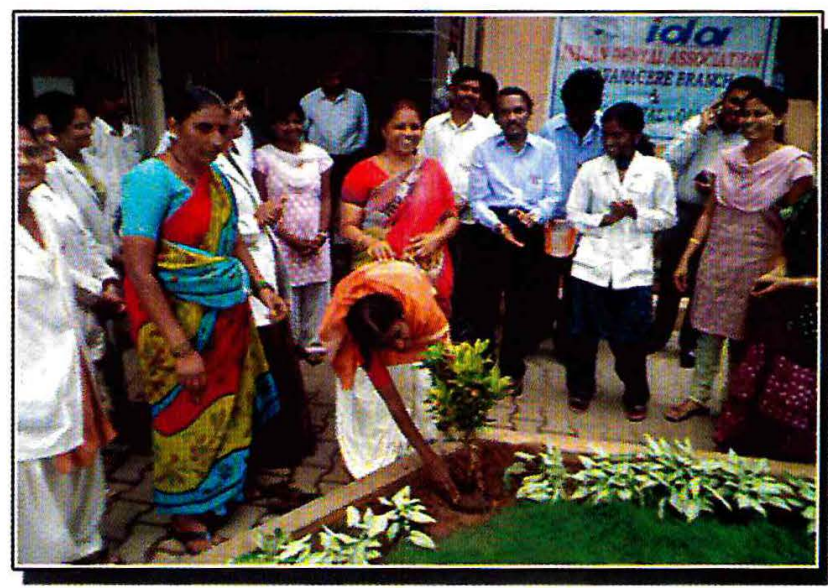

World environmental day held on $06 / 06 / 2011$ 